\title{
Pharmacokinetics of Oral Rosiglitazone in Taiwanese and Post Hoc Comparisons with Caucasian, Japanese, Korean, and Mainland Chinese Subjects
}

\author{
Kai-Min Chu', Oliver Yoa-Pu Hu², Li-Heng Pao ${ }^{3}$, Cheng-Huei Hsiong ${ }^{3}$ \\ ${ }^{1}$ Division of Cardiology, Department of Medicine, Tri-Service General Hospital, National Defense Medical Center. \\ ${ }^{2}$ Research and Development, National Defense Medical Center, Taipei, Taiwan, Republic of China. \\ ${ }^{3}$ Pharmaceutical Research Institute, National Defense Medical Center.
}

Received, December 12, 2006; Revised March 14, 2007; Accepted May 9, 2007.

\begin{abstract}
Purpose. Rosiglitazone, an insulin-sensitizing thiazolidinedione, acts as a ligand for the $\gamma$-subtype of the peroxisome proliferator-activated receptor in the regulation of glucose homeostasis and lipid metabolism. The aims of this study were to determine the pharmacokinetics of oral rosiglitazone in Taiwanese and to post hoc compare the ethnic differences among Caucasian, Japanese, Korean, and Mainland Chinese. Methods. Twelve Taiwanese healthy male subjects received 4 and 8 mg of rosiglitazone. Similar protocols were used in the previously unpublished studies conducted in 25 Caucasian, 32 Japanese, 8 Korean, and 12 Mainland Chinese healthy male subjects. The 4 mg dose data were used for ethnicity comparisons. Results. The respective pharmacokinetic properties of Taiwanese, Caucasian, Japanese, Korean and Mainland Chinese are: terminal half-life (hr): $4.18 \pm 0.43$, $3.96 \pm 1.31,3.83 \pm 0.78,4.70 \pm 1.19$ and $4.37 \pm$ $0.63 ; \mathrm{C}_{\max }(\mathrm{ng} / \mathrm{ml}): 384.1 \pm 59.3,260.2 \pm 75.7$, $401.9 \pm 102.3$, $345.3 \pm 60.6$, and $406.2 \pm 52.0$; $\mathrm{AUC}_{0 \text {-inf }}(\mathrm{h} \cdot \mathrm{ng} / \mathrm{ml}): 2078 \pm$ 433, $1249 \pm$ 566, 1901 \pm 397, $1938 \pm 534$, and $2158 \pm 498$. The $C_{\max }$ and $\mathrm{AUC}_{0 \text {-inf }}$ of Caucasian were significantly $(\mathrm{p}=$ $0.002,0.008$ ) lower and $\mathrm{CL} / \mathrm{F}$ and $\mathrm{V} / \mathrm{F}$ were significantly $(p=0.000,0.003)$ higher than those of other races. These differences of $\mathrm{C}_{\max }, \mathrm{AUC}_{0}$ inf, CL/F and V/F between Caucasian and other races became insignificant after normalized by dose and weight. Conclusions. In a given dose by body weight, ethnicity had no significant impact on the pharmacokinetics of rosiglitazone in normal healthy volunteers.
\end{abstract}

\section{INTRODUCTION}

Ethnic differences in drug response are considered to be important factors accounting for interindividual variations (1). For example, Chinese men have been shown to have greater sensitivity than white men to the effects of the same doses of propranolol on heart rate and blood pressure (2). Acetaminophen half- life is considerably longer (15-62\%), and oral clearance is lower (16- 56\%) in Hong Kong Chinese as compared to Australian Chinese, Caucasians, and subjects from Pakistan, Denmark, Spain and South Africa (3). Recent developments have improved understanding of the molecular mechanisms responsible for such interethnic differences. Genetic variations that may provide a molecular basis for ethnic differences in drug metabolizing enzymes (CYP 2C9 (4), 2C19 (5), 2D6 (6), and 3A4 (7)), drug transporter (Pglycoprotein (8), alpha-1 acid glycoprotein (9)), and drug receptors (adrenoceptors (10)). Their relevance for the clinical evaluation of drugs is attracting growing attention, especially, since the discussion on the acceptability of foreign clinical data has been set by the International Conference on Harmonization $(11,12)$. A pharmacokinetic study in the new region may be considered as a bridging study to allow extrapolation of foreign clinical data to the new region. This will minimize duplication of clinical studies and supply medicines expeditiously to patients for their benefit.

Thiazolidinediones are insulin-sensitizing agents that act as ligands for the $\gamma$-subtype of the peroxisome proliferator-activated receptor (PPAR- $\gamma$ ), which is directly involved in the regulation of genes controlling glucose

Corresponding Author: Dr. Kai-Min Chu, Associate Professor, Division of Cardiology, Department of Medicine, Tri-Service General Hospital, \#325, Section 2, Cheng-Gung Road, Taipei, Taiwan, Republic of China, E-mail: km chu@seed.net.tw 
homeostasis and lipid metabolism (13). Rosiglitazone, a thiazolidinedione, had been shown as an effective in the treatment of patients with type 2 diabetes in many countries $(14,15)$. It has been launched in the US in 1999 and in the UK and Europe in 2000.The purpose of this study was to determine the pharmacokinetics of oral rosiglitazone in healthy Taiwanese volunteers and to post hoc compare the possible ethnic differences among Asia-Pacific peoples and Caucasians.

\section{METHODS}

\section{Study protocol}

Twelve healthy male Taiwanese were enrolled in this study. All subjects were in good health on the basis of history, physical examination, urinalysis, blood chemistry, chest roentgenogram and electrocardiogram. None had a history of cardiovascular, renal, hepatic, gastrointestinal, respiratory, hematological, metabolic or other diseases that could affect the absorption, distribution, metabolism, or excretion of the study drug. The protocol was approved by the Human Subject Institutional Review Board. The study was carried out in accordance with the Declaration of Helsinki. Written informed consent was obtained after the purpose, procedures, and risks of the study had been explained to the volunteers. The volunteers were instructed to avoid any other drugs, including alcohol, caffeine or nicotine for two weeks before the study and during the study days.

This was an open label, randomized, twoperiod, oral dose, and crossover study. The subjects were randomized into two groups. Each subject received two doses of rosiglitazone (4 mg and $8 \mathrm{mg}$ ) with the different order arranged prior to the study. One dose was studied during one period. Each dosing period was separated by at least 7 days. The $8 \mathrm{mg}$ dose was administered as two 4 mg tablets.

Subjects were reported to the Clinical Research Unit prior to the dosing on the study day of each period after fasting for at least 10 hours. A heparin locked intravenous catheter was inserted in one forearm vein for 24 hours for blood collection. Rosiglitazone tablet(s) was swallowed as a whole and not chewed with 240 $\mathrm{ml}$ of water. No water or fluid was permitted for 2 hours after dosing. In the previously completed unpublished studies provided by SmithKline
Beecham Pharmaceuticals, Harlow, UK, the respective numbers of male healthy subjects were 25, 32, 8 and 12 for Caucasian, Japanese, Korean and Mainland Chinese. The inclusion and exclusion criteria were the same. All studies were also approved by the Human Subject Institutional Review Board and carried out in accordance with the Declaration of Helsinki. The time points of blood collection were exactly the same in studies in Taiwanese, Japanese and Korean. Blood samples $(5 \mathrm{ml})$ were collected into test tubes containing ethylenediamine tetraacetic acid (Sigma chemical company, St. Louis, MO) at 0 hour and then at $0.25,0.5,0.75,1,1.5,2,3,4,6$, 8, 12, 16 and 24 hours following dosing. The 0.75 hour time point was omitted in the study done in Mainland China. In Caucasian study, subjects were pooled from 4 different small studies with $n$ equals 6, 7, 8 and 4, respectively. Blood collection times of these 4 studies were slightly different. The 0.25 hour time point were omitted in 4 studies, 6 hour time point omitted in 1 study, 16 hour time point omitted in 1 study, and 2 studies had 48 hour time point. They all covered 24 hour time point. All blood samples after collection were immediately chilled on crushed ice. Symptoms and adverse drug reaction were spontaneously reported by the subjects and assessed by the nurse and the principle investigator throughout the study period.

\section{Sample Preparation}

Blood samples were centrifuged soon at $2000 \mathrm{~g}$ for 15 minutes at approximately $4^{\circ} \mathrm{C}$ after collection. The resultant plasma was transferred to a labeled plain polypropylene tube, and frozen immediately at approximately $-20^{\circ} \mathrm{C}$ to await assay.

\section{Assay Methodology}

Plasma samples of all races were assayed for rosiglitazone using protein precipitation followed by the validated LC/MS/MS analysis employing positive-ion electrospray ionization method at the same drug analysis laboratory, SmithKline Beecham Pharmaceuticals, Harlow, UK. The lower limit of quantification was $2.5 \mathrm{ng} / \mathrm{ml}$ (CV\% = 3.87), based on a $50 \mu \mathrm{l}$ aliquot of human plasma. QC samples were assayed with each batch of samples against separately prepared calibration standards. The results of the QC 
samples were used to assess the day-to-day performance of the assay. Raw data from each subject were used for obtaining the individual pharmacokinetic parameters.

\section{Pharmacokinetic Analysis}

Estimates of pharmacokinetic parameters of Rosiglitazone, such as the maximum observed plasma concentration $\left(\mathrm{C}_{\max }\right)$, the time to reach $\mathrm{C}_{\max }\left(\mathrm{T}_{\max }\right)$, area under the plasma concentrationtime curve from time zero to the time of the last quantifiable concentration $\left(\mathrm{AUC}_{0-\mathrm{t}}\right)$, AUC from time zero to infinity $\left(\mathrm{AUC}_{0 \text {-inf }}\right)$, area under the first moment curve from time zero to infinity $\left(\mathrm{AUMC}_{0 \text {-inf }}\right)$, elimination rate constant $\left(\mathrm{K}_{\mathrm{el}}\right)$, the terminal elimination half-life $\left(\mathrm{T}_{1 / 2}\right)$, mean resident time (MRT), oral clearance (CL/F), and oral volume of distribution (V/F) were determined using non-compartmental methods as implemented in the Kinetica computer program of MicroPharm International.

\section{Statistical Analysis}

The pharmacokinetic parameters of the two dose levels were compared by analysis of variance (ANOVA) (16). The ANOVA contained terms for subject, period and dose. For demonstrating the ethnic insensitivity of rosiglitazone, Taiwan subject data were compared with the data obtained from Caucasian, Japanese, Korean and Mainland Chinese. Method of multivariates analysis of variance with a general linear model in SPSS (17) was used for comparisons. The dependent variables were the above mentioned pharmacokinetic parameters, height, weight and age. Scheffe tests were used for Post Hoc multiple comparisons. $\mathrm{P}<0.05$ (two tailed) was considered significant. The observed power was determined after the study.

\section{RESULTS}

\section{Pharmacokinetic Study and Ethnic Comparisons}

The demographic data of healthy subjects in the pharmacokinetic studies in 5 races are shown in Table 1. The weights of Caucasian were significantly $(\mathrm{P}<0.01)$ higher than those of other races. The plasma concentration versus time curves in 5 different races before and after normalized with dose/weight are shown in Figures 1 and 2, respectively. The $\mathrm{C}_{\max }, \mathrm{T}_{\max }$, $\mathrm{AUC}_{0 \text {-inf }}, \mathrm{AUMC}_{0 \text {-inf, }} \mathrm{T}_{1 / 2}, \mathrm{~K}_{\mathrm{el}}, \mathrm{MRT}, \mathrm{CL} / \mathrm{F}, \mathrm{V} / \mathrm{F}$, $\mathrm{C}_{\text {max }} /\left(\right.$ dose/weight), $\quad \mathrm{AUC}_{0 \text {-inf }} /$ (dose/weight), CL/F/weight and V/F/weight of 5 different ethnic groups (Taiwanese, Caucasian, Japanese, Korean and Chinese) after single-dose oral administration of $4 \mathrm{mg}$ of rosiglitazone were shown in Table 2. The observed power was also shown. The $\mathrm{C}_{\max }$ and $\mathrm{AUC}_{0 \text {-inf }}$ of Caucasian were significantly ( $\mathrm{p}=$ $0.002,0.008$ ) lower and $\mathrm{CL} / \mathrm{F}$ and $\mathrm{V} / \mathrm{F}$ were significantly ( $p=0.000,0.003)$ higher than those of other races. After normalized with dose and body weight, the $\mathrm{C}_{\max } /\left(\right.$ dose/weight), $\mathrm{AUC}_{0 \text { - }}$ inf/(dose/weight), CL/F/weight and V/F/weight of Caucasian were not statistically different from those of other races. $(p=0.173,0.409,0.065$, 0.274) After attaining $\mathrm{C}_{\max }$, rosiglitazone concentrations declined in a monoexponential manner for all races ( 1$)$. The mean terminal elimination half-lives were between $3.83 \pm 0.78$ $\mathrm{hr}$ and $4.70 \pm 1.19 \mathrm{hr}$. Maximal concentrations of rosiglitazone were observed at approximately one hour after dose. The $\mathrm{C}_{\max }$ for the entire group were between $260.2 \pm 75.7 \mathrm{ng} / \mathrm{ml}$ (Caucasian) and $401.9 \pm 102.3 \mathrm{ng} / \mathrm{ml}$ (Japanese). The $\mathrm{AUC}_{0 \text {-inf }}$ for the entire group were $1429 \pm 566 \mathrm{ng} \cdot \mathrm{h} / \mathrm{ml}$ and $2158 \pm 498 \mathrm{ng} \cdot \mathrm{h} / \mathrm{ml}$. Other parameters are presented in Table 2 .

In the two dose-level $4 \mathrm{mg}$ and $8 \mathrm{mg}$ studies in Taiwanese, the plasma concentrations of rosiglitazone from 12 subjects are shown in Tables 3 and 4.

\section{Adverse Experiences}

No any adverse experience or serious adverse experience was observed in all subjects during the study periods.

\section{DISCUSSION}

There are several intrinsic factors including height, weight, age, race, genetic polymorphism of the drug metabolism and so on need to be concerned for possible ethnic difference (11). It is extensively metabolized by two major routes, N-demethylation and hydroxylation, followed by conjugation with sulfate and glucuronic acid (18). 
Table 1. Demographic data of healthy subjects in the pharmacokinetic studies with rosiglitazone in 5 races.

\begin{tabular}{llrrrrr} 
& & Taiwanese & Caucasian & Japanese & Korean & Chinese \\
\hline N & & 12 & 25 & 32 & 8 & 12 \\
Height & Mean & 173.4 & 179.7 & 169.7 & 175.6 & 172.6 \\
$(\mathrm{~cm})$ & SD & 6.5 & 6.8 & 6.9 & 5.3 & 4.6 \\
& & & & & & \\
& (minimum, maximum) & $(159,182)$ & $(168,200)$ & $(157,186)$ & $(169,182)$ & $(166,179)$ \\
Weight & Mean & & & & & \\
(kg) & SD & 64.1 & $77.5 *$ & 65.4 & 66.9 & 68.3 \\
& (minimum, maximum) & $(53.5,71.0)$ & $(54.3,109.0)$ & $(50.6,80.8)$ & $(57.0,80.0)$ & $(61.2,77.2)$ \\
Age & Mean & 22.3 & 28.8 & 27.9 & 24.4 & 22.1 \\
$(y)$ & SD & 1.7 & 8.9 & 8.9 & 1.7 & 1.3 \\
& (minimum, maximum) & $(20,26)$ & $(22,56)$ & $(20,52)$ & $(21,26)$ & $(19,24)$ \\
\hline
\end{tabular}

*: $\mathrm{p}<0.01$ of the analysis of variance and Sheffe’s multiple comparisons with data of Taiwanese.

\section{Concentration of rosiglitazone}

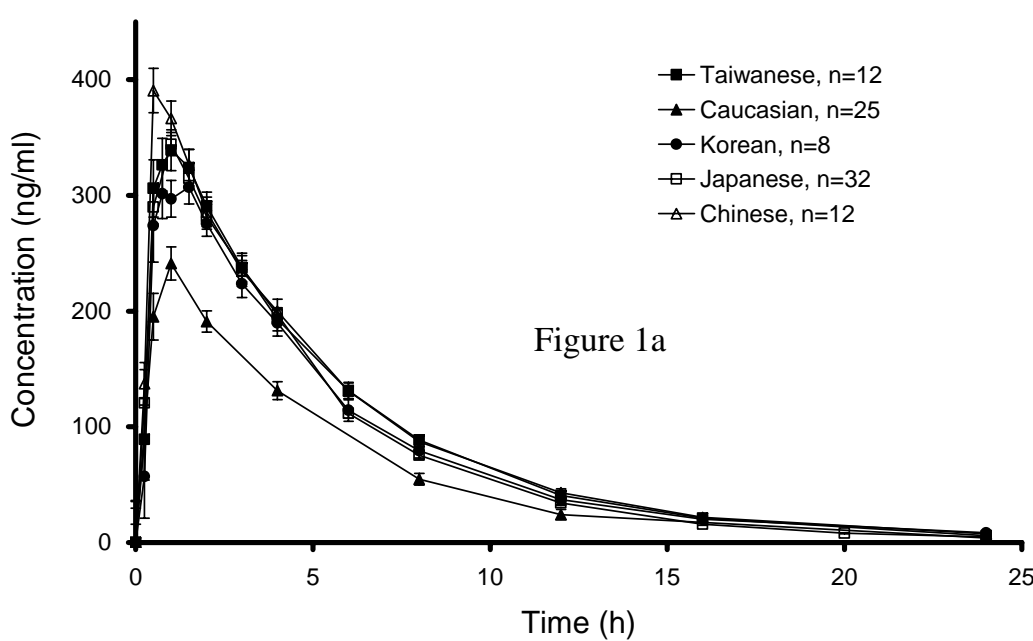

Concentration of rosiglitazone

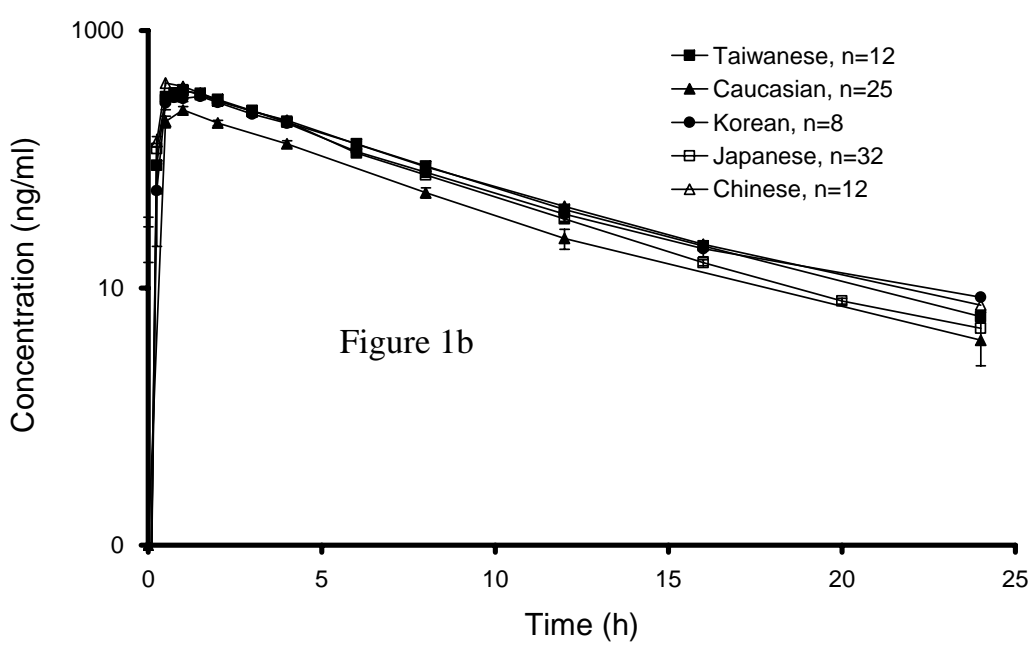

Figure 1. These plots show the mean \pm SE of the concentration-time curves of rosiglitazone in healthy male subjects of Taiwanese, Caucasian, Japanese, Mainland Chinese and Korean after oral administration of $4 \mathrm{mg}$ of Rosiglitazone ((a) normal and (b) semi-logarithmic coordinate). 
Table 2. Ethnic comparisons in pharmacokinetic parameters (mean \pm SD) in healthy subjects of 5 races after administration of 4 mg or 8 mg of rosiglitazone.

\section{Parameters}

Race

\begin{tabular}{|c|c|c|c|c|c|c|c|c|c|c|c|c|c|c|c|c|c|c|c|}
\hline (unit) & Taiwa & ese & (4 mg) & Taiwa & les & (8 mg) & Cauca & ian & 4 mg) & Japaı & 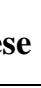 & mg) & Kore & 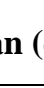 & mg) & Chir & 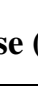 & mg) & $\begin{array}{c}\text { Observed } \\
\text { power }\end{array}$ \\
\hline $\mathbf{N}$ & 12 & & & 12 & & & 25 & & & 25 & & & 8 & & & 12 & & & \\
\hline $\mathbf{C}_{\max }(\mathrm{ng} / \mathrm{ml})$ & 384.1 & \pm & 59.3 & 724.3 & \pm & 135.7 & $260.2^{*}$ & \pm & 75.7 & $260.2^{*}$ & \pm & 75.7 & 345.3 & \pm & 60.0 & 406.2 & \pm & 52.0 & 1 \\
\hline $\mathbf{T}_{\max }(\mathrm{h})$ & 0.9 & \pm & 0.4 & 1.0 & \pm & 0.6 & 0.9 & \pm & 0.4 & 0.9 & \pm & 0.4 & 1.0 & \pm & 0.5 & 0.7 & \pm & 0.3 & 0.214 \\
\hline $\mathbf{A U C}_{0 \text {-inf }}(\mathrm{h} \cdot \mathrm{ng} / \mathrm{ml})$ & 2078 & \pm & 433 & 4024 & \pm & 956 & $1429 *$ & \pm & 566 & $1429 *$ & \pm & 566 & 1938 & \pm & 534 & 2158 & \pm & 498 & 0.991 \\
\hline AUMC $_{0 \text {-inf }}\left(\mathrm{h}^{2} \cdot \mathrm{ng} / \mathrm{ml}\right)$ & 12116 & \pm & 3836 & 24021 & \pm & 8739 & 8443 & \pm & 6502 & 8443 & \pm & 6502 & 12388 & \pm & 7146 & 12856 & \pm & 4936 & 0.657 \\
\hline $\mathbf{K}_{\mathrm{el}}(\mathrm{l} / \mathrm{h})$ & 0.17 & \pm & 0.02 & 0.17 & \pm & 0.02 & 0.19 & \pm & 0.05 & 0.19 & \pm & 0.05 & 0.16 & \pm & 0.04 & 0.16 & \pm & 0.02 & 0.704 \\
\hline $\mathbf{T}_{1 / 2}(\mathrm{~h})$ & 4.18 & \pm & 0.43 & 4.19 & \pm & 0.56 & 3.96 & \pm & 1.31 & 3.96 & \pm & 1.31 & 4.70 & \pm & 1.19 & 4.37 & \pm & 0.63 & 0.527 \\
\hline MRT (h) & 5.73 & \pm & 0.70 & 5.84 & \pm & 0.80 & 5.46 & \pm & 1.58 & 5.46 & \pm & 1.58 & 6.05 & \pm & 1.57 & 5.80 & \pm & 1.03 & 0.393 \\
\hline CL/F (l/h) & 2.00 & \pm & 0.41 & 2.08 & \pm & 0.46 & $3.16^{*}$ & \pm & 1.03 & $3.16^{*}$ & \pm & 1.03 & 2.18 & \pm & 0.52 & 1.96 & \pm & 0.52 & 1 \\
\hline $\mathbf{V} / \mathbf{F}(\mathrm{l})$ & 11.90 & \pm & 1.77 & 12.41 & \pm & 2.34 & $17.09^{*}$ & \pm & 5.78 & $17.09 *$ & \pm & 5.78 & 14.07 & \pm & 1.33 & 12.05 & \pm & 2.16 & 0.999 \\
\hline $\begin{array}{l}\mathbf{C}_{\text {max }} / \text { (dose/weight) } \\
(\mathrm{ng} / \mathrm{ml}) /(\mathrm{mg} / \mathrm{kg})\end{array}$ & 6110.2 & \pm & 787.5 & 5798.2 & \pm & 1191.7 & 4959.4 & \pm & 1314.0 & 4959.4 & \pm & 1314.0 & 5725.9 & \pm & 823.6 & 6883.8 & \pm & 628.6 & 0.992 \\
\hline $\begin{array}{l}\text { AUC }_{0 \text {-inf }} /(\text { dose/weight) } \\
(\mathrm{h} \cdot \mathrm{ng} / \mathrm{ml}) /(\mathrm{mg} / \mathrm{kg})\end{array}$ & 32944 & \pm & 5739 & 32176 & \pm & 7695 & 27330 & \pm & 10493 & 27330 & \pm & 10493 & 31863 & \pm & 6331 & 36549 & \pm & 7990 & 0.774 \\
\hline $\begin{array}{l}\text { CL/F/weight } \\
(\mathrm{l} / \mathrm{h}) /(\mathrm{kg})\end{array}$ & 0.031 & \pm & 0.005 & 0.033 & \pm & 0.008 & 0.041 & \pm & 0.013 & 0.034 & \pm & 0.008 & 0.032 & \pm & 0.006 & 0.029 & \pm & 0.006 & 0.945 \\
\hline $\begin{array}{l}\text { V/F/weight } \\
\text { (l)/(kg) }\end{array}$ & 0.186 & \pm & 0.020 & 0.195 & \pm & 0.046 & 0.222 & \pm & 0.070 & 0.183 & \pm & 0.036 & 0.211 & \pm & 0.017 & 0.176 & \pm & 0.027 & 0.865 \\
\hline
\end{tabular}

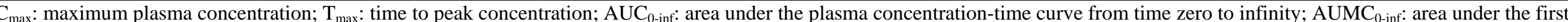

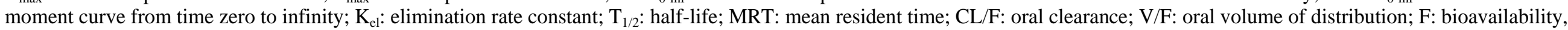
$*: \mathrm{p}<0.01$ of the analysis of variance and Sheffe's multiple comparison with the $4 \mathrm{mg}$ data of Taiwanese 
Table 3: The plasma concentrations (ng/ml) of rosiglitazone in 12 Taiwanese healthy subjects after administration of single dose of 4 mg of rosiglitazone

\begin{tabular}{ccccccccccccccccccc} 
Time & Subject 1 & Subject 2 & Subject 3 & Subject 4 & Subject 5 & Subject 6 & Subject 7 & Subject 8 & Subject 9 Subject 10 Subject 11 Subject 12 & Mean & SD \\
\hline 0.25 & 29.75 & 83.9 & 74.31 & 6.33 & $*$ & 241.88 & 18.42 & $*$ & 33.79 & 296 & $*$ & 18.21 & 89.18 & 105.98 \\
0.5 & 273.51 & 305.59 & 444.17 & 87.47 & 143.03 & 273.14 & 251.9 & $*$ & 370.57 & 357.5 & 440.5 & 419.68 & 306.10 & 116.75 \\
0.75 & 308.97 & 366.62 & 445.95 & 299.68 & 158.13 & 373.54 & 311.78 & 193.72 & 372.32 & 346.78 & 441.21 & 300.07 & 326.56 & 86.17 & \\
1 & 300.09 & 342.29 & 419.01 & 482.73 & 161.53 & 329.88 & 306.13 & 343.36 & 341.69 & 345.57 & 404.99 & 292.47 & 339.15 & 78.53 \\
1.5 & 279.06 & 307.99 & 364.27 & 446.8 & 299.26 & 298.85 & 270.79 & 426.55 & 295.54 & 313.51 & 341.25 & 245.45 & 324.11 & 61.02 \\
2 & 250.49 & 276.55 & 300.77 & 384.19 & 302.72 & 279.58 & 238.82 & 393.95 & 240.17 & 282.47 & 317.74 & 222.31 & 290.81 & 54.20 \\
3 & 209.52 & 225.02 & 270.64 & 272.58 & 258.37 & 233.21 & 204.99 & 330.17 & 186.64 & 217.26 & 258.55 & 185.87 & 237.74 & 42.07 \\
4 & 186.44 & 188.48 & 203.56 & 256.51 & 227.89 & 136.57 & 149.45 & 268.01 & 155.64 & 172.54 & 218.13 & 152.25 & 192.96 & 42.89 \\
6 & 100.87 & 118.3 & 120.3 & 201.04 & 145.38 & 165.54 & 100.52 & 173.56 & 92.18 & 115.96 & 142.62 & 97.46 & 131.14 & 34.67 \\
8 & 66.03 & 81.83 & 87.19 & 123.22 & 102.65 & 111.14 & 63.24 & 126.51 & 60.35 & 79.78 & 97.07 & 63.08 & 88.51 & 23.63 \\
12 & 32.98 & 33.16 & 38.87 & 41.34 & 53.36 & 50.92 & 28.67 & 72.41 & 24.74 & 35.33 & 51.16 & 25.52 & 40.71 & 14.01 \\
16 & 12.13 & 18.6 & 19.73 & 23.79 & 27.41 & 36.19 & 12.46 & 40.03 & 10.54 & 16.98 & 25.7 & 9.72 & 21.11 & 9.89 \\
24 & 3.32 & 3.96 & 5.08 & 5.97 & 6.09 & 10.83 & 3.78 & 12.68 & 3.45 & 5.28 & 8.37 & 2.57 & 5.95 & 3.15 \\
\hline
\end{tabular}

* Data are below the low limit of quantification.

Table 4: The plasma concentrations (ng/ml) of rosiglitazone in 12 Taiwanese healthy subjects after administration of single dose of 8 mg of rosiglitazone.

\begin{tabular}{|c|c|c|c|c|c|c|c|c|c|c|c|c|c|c|}
\hline Time & Subject 1 & Subject 2 & Subject 3 & Subject 4 & Subject 5 & Subject 6 & Subject 7 & 7 Subject 8 & Subject 9 & Subject 10 & Subject 11 & Subject 12 & Mean & SD \\
\hline 0.25 & 25.13 & 178.53 & 87.01 & 285.13 & 217.56 & 311.15 & 177.88 & 5.39 & 9.25 & 250.35 & 27.52 & 105.01 & 139.99 & 111.42 \\
\hline 0.5 & 153.99 & 794.04 & 578.12 & 891.66 & 550.12 & 990.37 & 782.91 & 215.94 & 63.15 & 530.55 & 170.44 & 790.88 & 542.68 & 320.87 \\
\hline 0.75 & 343.34 & 761.87 & 619.87 & 754.13 & 501.84 & 625.89 & 719.97 & 551.56 & 241.48 & 692.84 & 466.35 & 748.99 & 585.68 & 170.03 \\
\hline 1 & 366.37 & 706.6 & 648.06 & 887.07 & 471.55 & 792.81 & 659.19 & 752.3 & 384.16 & 672.67 & 618.65 & 669.3 & 635.73 & 157.46 \\
\hline 1.5 & 555.92 & 618.04 & 579.54 & 752.26 & 401.59 & 870.12 & 539.94 & 754.39 & 454.33 & 574.81 & 658.85 & 571.39 & 610.93 & 131.55 \\
\hline 2 & 580.85 & 547.19 & 491.43 & 631.54 & 471.66 & 749.08 & 500.01 & 722.18 & 556.22 & 549.49 & 651.42 & 523.18 & 581.19 & 89.61 \\
\hline 3 & 424.41 & 494.91 & 372.64 & 557.86 & 336.96 & 722.17 & 447.16 & 593.74 & 485.61 & 445.94 & 536.89 & 458.1 & 489.70 & 103.49 \\
\hline 4 & 367.12 & 405.91 & 260.51 & 424.17 & 284.93 & 458.06 & 372.91 & 497.95 & 399.63 & 371.38 & 424.43 & 373.16 & 386.68 & 66.13 \\
\hline
\end{tabular}


Table 4 continued...

\begin{tabular}{|c|c|c|c|c|c|c|c|c|c|c|c|c|c|c|}
\hline 6 & 201.15 & 243.99 & 148.38 & 326.52 & 161.08 & 409.28 & 233.58 & 329.68 & 255.19 & 223.75 & 276.35 & 236.39 & 253.78 & 73.81 \\
\hline 8 & 124.11 & 175.7 & 87.62 & 249.57 & 178.12 & 190.33 & 160.03 & 216.88 & 173.39 & 148.99 & 182.57 & 148.66 & 169.66 & 41.67 \\
\hline 12 & 46.12 & 79.59 & 31.18 & 107.14 & 91.28 & 137.01 & 74.74 & 129.17 & 71.68 & 63.59 & 85.5 & 61.63 & 81.55 & 31.29 \\
\hline 16 & 20.85 & 36.29 & 16.2 & 56.92 & 31.14 & 97.84 & 38.33 & 64.26 & 32.56 & 29.81 & 40.24 & 29.29 & 41.14 & 22.37 \\
\hline 24 & 4.93 & 9.68 & 3.87 & 12.43 & 15.28 & 34.43 & 10.89 & 20.7 & 6.92 & 8.82 & 11.87 & 8.36 & 12.35 & 8.31 \\
\hline
\end{tabular}
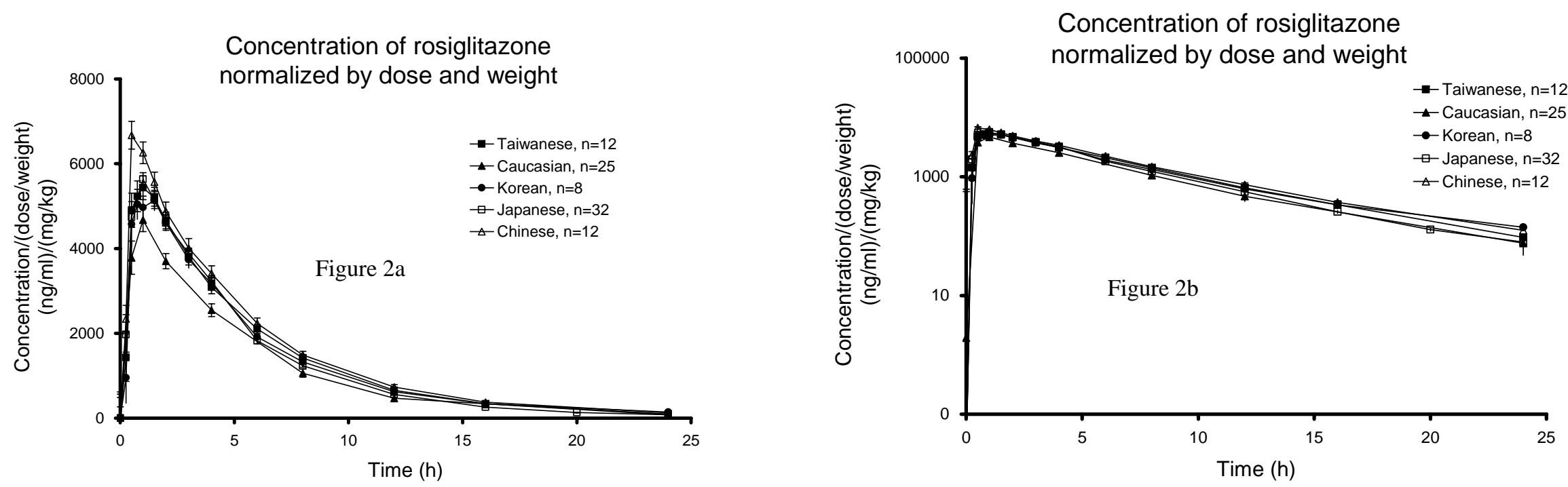

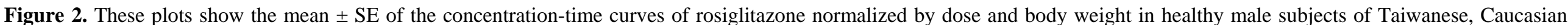
Japanese, Mainland Chinese and Korean after oral administration of 4 mg of Rosiglitazone ((a) normal and (b) semi-logarithmic coordinate). 
In addition, there were many quite diverse ethnic groups in "Mainland Chinese". The Taiwanese were also immigrant Chinese. This study was not planned to determine the polymorphism.

In Taiwanese study, although it was not specifically designed to provide a formal assessment of dose proportionality, the pharmacokinetics of rosiglitazone exhibited linearity in the range 4 to $8 \mathrm{mg}$ in these healthy male subjects. Increases in both $\mathrm{C}_{\max }$ and $\mathrm{AUC}_{0-}$ inf were approximately proportional to the increase in dose over the range of 4 to $8 \mathrm{mg}$. At two dose levels, rosiglitazone was rapidly absorbed, terminal phase elimination half-lives were similar for all subjects receiving two doses with values ranging from 3.51 to 5.58 hours. There were no gross differences in parameters of absorption and elimination, $\mathrm{T}_{\max }$ and $\mathrm{T}_{1 / 2}$, respectively across the range of doses. Inter-subject variability was generally low, with coefficients of variation generally less than $30 \%$ for $\mathrm{C}_{\max }$ and $\mathrm{AUC}_{0 \text {-inf }}$ at the 4 and $8 \mathrm{mg}$ doses.

In summary, there was no adverse experience or serious adverse experience in all subjects during all of the study periods. The pharmacokinetic parameters showed no difference among Taiwanese, Japanese, Korean, and Mainland Chinese normal healthy volunteers after single oral administration of $4 \mathrm{mg}$ of rosiglitazone. Caucasian had lower $\mathrm{C}_{\max }$ and AUC but became not significant after normalization by body weight.

\section{ACKNOWLEDGMENTS}

Authors thank SmithKline Beecham Pharmaceuticals for supporting this study, providing the raw data of previously unpublished studies and plasma sample analysis. The protocol was initiated by SmithKline Beecham and revised by authors. The conduction, pharmacokinetic analysis and manuscript preparation were not supported.

\section{REFERENCES}

[1] Johnson JA. Influence of race or ethnicity on pharmacokinetics of drugs. J Pharm Sci, 86 (12): 1328-1333, 1997.

[2] Zhou HH, Koshakji RP, Silberstein DJ, Wilkinson GR, Wood AJ. Altered sensitivity to and clearance of propranolol in men of Chinese descent as compared with American whites. N Engl J Med, 320 (9): 565-570, 1989.
[3] Yin OQ, Tomlinson B, Chow AH, Chow MS. Pharmacokinetics of acetaminophen in Hong Kong Chinese subjects. Int J Pharm, 222 (2): 305-308, 2001.

[4] Takahashi H, Echizen H. Pharmacogenetics of CYP2C9 and interindividual variability in anticoagulant response to warfarin. Pharmacogenomics J, 3 (4): 202-14, 2003.

[5] Jiang ZP, Shu Y, Chen XP, Huang SL, Zhu RH, Wang W, He N, Zhou HH. The role of CYP2C19 in amitriptyline N-demethylation in Chinese subjects. Eur J Clin Pharmacol, 58 (2): 109-13, 2002.

[6] Yoon YR, Cha IJ, Shon JH, Kim KA, Cha YN, Jang IJ, Park CW, Shin SG, Flockhart DA, Shin JG. Relationship of paroxetine disposition to metoprolol metabolic ratio and CYP2D6*10 genotype of Korean subjects. Clin Pharmacol Ther, 67 (5): 567-576, 2000.

[7] Chowbay B, Cumaraswamy S, Cheung YB, Zhou Q, Lee EJ. Genetic polymorphisms in MDR1 and CYP3A4 genes in Asians and the influence of MDR1 haplotypes on cyclosporin disposition in heart transplant recipients. Pharmacogenetics, 13 (2): 89-95, 2003.

[8] Mancinelli LM, Frassetto L, Floren LC, Dressler D, Carrier S, Bekersky I, Benet LZ, Christians U. The pharmacokinetics and metabolic disposition of tacrolimus: a comparison across ethnic groups. Clin Pharmacol Ther, 69 (1): 24-31, 2001.

[9] Sadler BM, Gillotin C, Lou Y, Stein DS. In vivo effect of alpha(1)-acid glycoprotein on pharmacokinetics of amprenavir, a human immunodeficiency virus protease inhibitor. Antimicrob Agents Chemother, 45 (3): 852856, 2001.

[10] Vincent J, Elliott HL, Meredith PA, Reid JL. Racial differences in drug responses--a comparative study of trimazosin and alpha 1adrenoceptor responses in normotensive Caucasians and West Africans. $\mathrm{Br} \mathrm{J}$ Clin Pharmacol, 21 (4): 401-408, 1986.

[11] Johnson JA. Predictability of the effects of race or ethnicity on pharmacokinetics of drugs. Int J Clin Pharmacol Ther, 38 (2): 5360, 2000.

[12] International Conference on Harmonisation; guidance on ethnic factors in the acceptability of foreign clinical data; availability--FDA. Notice. Fed Regist, 63 (111): 31790-31796, 1998.

[13] Lehmann JM, Moore LB, Smith-Oliver TA, Wilkison WO, Willson TM, Kliewer SA. An antidiabetic thiazolidinedione is a high affinity ligand for peroxisome proliferatoractivated receptor gamma (PPAR gamma). J Biol Chem, 270 (22): 12953-12956, 1995.

[14] Lebovitz HE, Dole JF, Patwardhan R, 
Rappaport EB, Freed MI. Rosiglitazone monotherapy is effective in patients with type 2 diabetes. J Clin Endocrinol Metab, 86 (1): 280-288, 2001.

[15] Balfour JA, Plosker GL. Rosiglitazone. Drugs, 57 (6): 921-930, 1999.

[16] Snedecor GW, Cochran WG. Statistical methods. 7th edition ed: The Iowa State University Press, 1982.

[17] SPSS Inc. SPSS Base 9.0 syntax reference guide. Chicago: Spss, p. ix, 1147, 1999.

[18] Cox PJ, Ryan DA, Hollis FJ, Harris AM, Miller AK, Vousden M, Cowley $\mathrm{H}$. Absorption, disposition, and metabolism of rosiglitazone, a potent thiazolidinedione insulin sensitizer, in humans. Drug Metab Dispos, 28 (7): 772-780, 2000.

[19] Baldwin SJ, Clarke SE, Chenery RJ. Characterization of the cytochrome P450 enzymes involved in the in vitro metabolism of rosiglitazone. Br J Clin Pharmacol, 48 (3): 424-432, 1999.

[20] Di Cicco RA, Miller AK, Patterson S, Freed MI. Rosiglitazone does not affect the steadystate pharmacokinetics of digoxin. J Clin Pharmacol, 40 (12 Pt 2): 1516-1521, 2000.

[21] Di Cicco RA, Allen A, Carr A, Fowles S, Jorkasky DK, Freed MI. Rosiglitazone does not alter the pharmacokinetics of metformin. $\mathrm{J}$ Clin Pharmacol, 40 (11): 1280-1285, 2000.

[22] Miller AK, DiCicco RA, Freed MI. The effect of ranitidine on the pharmacokinetics of rosiglitazone in healthy adult male volunteers. Clin Ther, 24 (7): 1062-71, 2002.

[23] Harris RZ, Inglis AM, Miller AK, Thompson KA, Finnerty D, Patterson S, Jorkasky DK,
Freed MI. Rosiglitazone has no clinically significant effect on nifedipine pharmacokinetics. J Clin Pharmacol, 39 (11): 1189-1194, 1999.

[24] Inglis AM, Miller AK, Culkin KT, Finnerty D, Patterson SD, Jorkasky DK, Freed MI. Lack of effect of rosiglitazone on the pharmacokinetics of oral contraceptives in healthy female volunteers. J Clin Pharmacol, 41 (6): 683-690, 2001.

[25] Miller AK, Inglis AM, Culkin KT, Jorkasky DK, Freed MI. The effect of acarbose on the pharmacokinetics of rosiglitazone. Eur J Clin Pharmacol, 57 (2): 105-109, 2001.

[26] Freed MI, Allen A, Jorkasky DK, DiCicco RA. Systemic exposure to rosiglitazone is unaltered by food. Eur J Clin Pharmacol, 55 (1): 53-56, 1999.

[27] Thompson-Culkin K, Zussman B, Miller AK, Freed MI. Pharmacokinetics of rosiglitazone in patients with end-stage renal disease. $\mathrm{J}$ Int Med Res, 30 (4): 391-9, 2002.

[28] Park JY, Kim KA, Kang MH, Kim SL, Shin JG. Effect of rifampin on the pharmacokinetics of rosiglitazone in healthy subjects. Clin Pharmacol Ther, 75 (3): 157-62, 2004.

[29] Niemi M, Backman JT, Neuvonen PJ. Effects of trimethoprim and rifampin on the pharmacokinetics of the cytochrome P450 2C8 substrate rosiglitazone. Clin Pharmacol Ther, 76 (3): 239-49, 2004.

[30] Park JY, Kim KA, Shin JG, Lee KY. Effect of ketoconazole on the pharmacokinetics of rosiglitazone in healthy subjects. $\mathrm{Br} \mathrm{J}$ Clin Pharmacol, 58 (4): 397-402, 2004. 